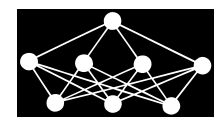

\title{
A NEURAL NETWORK APPROACH FOR ASSESSING THE RELATIONSHIP BETWEEN GRIP STRENGTH AND HAND ANTHROPOMETRY
}

\author{
Erman Çakıt, Behice Durgun†, Oya Cetik
}

\begin{abstract}
This study aimed to determine grip strength data for Turkish dentistry students and developed prediction models that allow: i) investigation of the relationship between grip strength and hand anthropometry using artificial neural networks (ANNs) and stepwise regression analysis, ii) prediction of the grip strength of Turkish dentistry students, and iii) assessment of the potential impact of hand anthropometric variables on grip strength. The study included 153 right-handed dentistry students, consisting of 81 males and 72 females. From 44 anthropometric and biomechanical measurements obtained from the right hands of the participants; five anthropometric measurements were selected for ANN and regression modeling using stepwise regression analysis. We included stepwise regression analysis results to assess the predictive power of the neural network approach, in comparison to a classical statistical approach. When the model accuracy was calculated based on the coefficient of determination $\left(R^{2}\right)$, the root mean squared error (RMSE) and the mean absolute error (MAE) values for each of the models, ANN showed greater predictive accuracy than regression analysis, as demonstrated by experimental results. For the best performing ANN model, the testing values of the models correlated well with actual values, with a coefficient of determination $\left(R^{2}\right)$ of 0.858 . Using the best performing ANN model, sensitivity analysis was applied to determine the effects of hand dimensions on grip strength and to rank these dimensions in order of importance. The results suggest that the three most sensitive input variables are the forearm length, the hand breadth and the finger circumference at the first joint of digit 5 and that the ANNs are promising techniques for predicting hand grip strength based on hand breadth, finger breadth, hand length, finger circumference and forearm length.
\end{abstract}

Key words: hand dimensions, grip strength, artificial neural network, stepwise regression analysis, sensitivity analysis

Received: September 9, 2014

DOI: $10.14311 / \mathrm{NNW} .2015 .25 .030$

Revised and accepted: May 16, 2015

\footnotetext{
${ }^{*}$ Erman Çakıt - Corresponding author, Department of Industrial Engineering, Aksaray University, 68100, Aksaray, Turkey, E-mail: ermancakit@aksaray.edu.tr

${ }^{\dagger}$ Behice Durgun, Anatomy Department, Cukurova University, Adana, Turkey, E-mail: bdurgun@cu.edu.tr

$\ddagger$ Oya Cetik, Department of Industrial Engineering, Cukurova University, Adana, Turkey, Email: oyacetik@cu.edu.tr
} 


\section{Introduction}

Hands are naturally essential for daily activities such as pushing, supporting the body in space or manipulating objects [19]. It is thus important to use hand anthropometry to design objects that will be used by human hands. Examples of such objects are machine guards, hand tools, and luggage handles [37]. As grip is necessary for most of the daily physical activities, grip strength is frequently considered in clinical settings as an indicator of overall physical strength and health $[2,25,33]$. Human grip strength is required for operating equipment in production and processing activities. For these reasons, the assessment of grip strength is crucial in order to provide information about work capacity. This information can be considered useful for designing equipment, workstations, and tasks to fit the grip strength of distinct populations by reducing the requirement for force to accord with the muscular strength [4].

Due to the lack of hand anthropometrics and grip strength data for the Turkish population, most of the hand tools used in Turkey are made in countries like the United States of America, Japan, the United Kingdom, Taiwan and China, and these imported hand tools have been designed based on the user anthropometrics of the exporting nation. A recent study has provided insights about Turkish hand dimensions and biomechanics relevant to the design of dental tools meant for the Turkish population [3], which is obviously of great interest to Turkish dentists.

The effect of demographic characteristics and anthropometric measurements on hand grip strength has been investigated in several studies including analyzing the correlations between hand dimensions and maximal grip strength and investigating the effects of handle grip span and user's hand dimension on maximum grip strength [23]. Predictive models were developed for predicting grip strength [45]; estimating hand length and grip strength [28]; estimating peak pinch strength [12]; estimating grip strength and endurance [33]; estimating grip strength [49], and modeling grip strength [32] using different methodologies. Regression analysis was conducted to estimate grip strength using other strength measurements rather than body dimensions [9, 11]. A non-linear statistical approach has been applied to predict strength using age parameter [47].

This study aimed to determine grip strength data for Turkish dentistry students and developed predictive models that allow: i) investigation of the relationship between grip strength and hand anthropometry using ANNs and stepwise regression analysis, ii) prediction of the grip strength of Turkish dentistry students, and iii) assessment of the potential impact of hand anthropometric variables on grip strength. The performance of proposed models in this study was compared to a classical statistical approach to gain an idea about the predictive power of the neural network approach in terms of accuracy of prediction. Three such criteria are here denoted by coefficient of determination $\left(R^{2}\right)$, root mean square error (RMSE), and mean absolute error (MAE) values. 
Çakıt E. et al: A neural network approach for assessing the relationship...

\section{Material and methodology}

\subsection{Participants}

The study groups comprised 153 healthy dentistry students (81 males, 72 females). The population was aged between 18 and 30 years. The average values and standard deviations of age, height and weight of the subjects were $22.06 \pm 2.14$ years, 169.83 $\pm 8.80 \mathrm{~cm}$, and $67.41 \pm 12.72 \mathrm{~kg}$, respectively. To make our study sample as homogeneous as possible, three left-handed students were excluded at the beginning of the study. Therefore, all the participants were right-handed, and measurements were taken for the right hand only. The participants were informed about the study and they each indicated their willingness to participate by signing a 'Consent to Participate' form. This study was approved by the Institutional Review Board for Research with Human Subjects at Cukurova University. At the time of the study, none of the participants reported a hand injury or disability. Three researchers were trained to take the measurements in this survey by practicing on themselves. Measurements were taken daily between 08:00 to 17:00 and data were collected over a period of two months.

\subsection{Apparatus and measurements}

Forty-four hand anthropometric and biomechanics measurements were obtained from right hands. Five anthropometric measurements were selected from these forty-four variables measurements for estimating grip strength as inputs for the ANN model development, these being hand breadth, finger breadth, finger circumference, hand length, and forearm length.

Hand breadth and finger breadth were measured using an electronic digital caliper, with an accuracy of $0.01 \mathrm{~mm}$ (Fig. 1(a) and 1(b)); hand length and forearm length were measured using a digital tape measure, with an accuracy of $1 \mathrm{~mm}$ (Fig. 1(d) and 1(e)); finger circumference of the first digit was measured using a finger circumference gauge, with an accuracy of $1.58 \mathrm{~mm}$ (Fig. 1(c)). Grip strength was measured using a Baseline digital handgrip dynamometer (Baseline Corp., Irvington, New York). Grip strength testing was conducted in accordance with the guidelines previously stated by the American Society of Hand Therapists [15]. Participants were seated, with the elbow against the side of the body and the lower arm at a right angle to the body (Fig. 1(f)). The hand was parallel to the body and the wrist was bent slightly backward. The span was adjustable with five different grip distances available depending on comfortable gripping. The comfortable position of the grip span for participants was between $35 \mathrm{~mm}$ and 59 mm. and participants performed three grip tests with a 1-minute rest between trials. It is recommended that three seconds or less is usually sufficient to register a maximum reading [43]. In our study, participants were instructed to squeeze gradually and continuously for at least two seconds and were encouraged to do their best when performing the tests.

The measurements were recorded in kilograms and the averaged grip strength measures were analyzed. Before testing, the examiner (the first author) demonstrated how to operate the dynamometer. The definitions and technique of measurements correspond to existing guidelines [29, 18] and these are summarized 


\begin{tabular}{ll}
\hline $\begin{array}{l}\text { Hand dimensions }[\mathrm{mm}] \text { and grip } \\
\text { strength }[\mathrm{kg}]\end{array}$ & Definition \\
\hline (1) Hand breadth across thumb & $\begin{array}{l}\text { The breadth of the hand measured at } \\
\text { the level of the distal end of the first } \\
\text { metacarpal of the thumb. }\end{array}$ \\
(2) Breadth at first joint of digit 5 & $\begin{array}{l}\text { Hand is extended and palm is facing } \\
\text { down; maximum breadth of the first joint } \\
\text { of digit. }\end{array}$ \\
(3) Circumference at first joint & $\begin{array}{l}\text { Hand is extended and palm is facing } \\
\text { down; maximum circumference of the first } \\
\text { joint of digit. } \\
\text { The distance from the base of the hand } \\
\text { to the top of the middle finger measured } \\
\text { along the long axis of the hand. } \\
\text { The distance from the tip of the elbow to } \\
\text { the tip of the styloid process of the radius. } \\
\text { The shoulder is adducted and neutrally } \\
\text { rotated, the elbow flexed to 90 degrees, } \\
\text { and the forearm and wrist is in a neutral } \\
\text { position. }\end{array}$ \\
(5) Forearm length & \\
(6) Hand grip strength &
\end{tabular}

Tab. I Hand dimensions and grip strength definition [19, 20].

in Tab. I. In this study, we only included the measurement details for five hand dimensions and grip strength data, please refer to a recent study [3] for all the measurements and definitions used.

\subsection{Methods}

\subsubsection{Stepwise regression analysis}

Regression analysis is used to estimate the relationship among variables including a dependent variable and one or more independent variables. More specifically, regression analysis tries to explain variations in the dependent variable y through movements in the $k$ explanatory (independent) variables $x_{1}, x_{2}, \ldots, x_{k}$. The general form of the linear regression model is:

$$
\begin{gathered}
y_{i}=f\left(x_{i 1}, x_{i 2}, \ldots, x_{i k}\right)+\epsilon_{i}, \\
y_{i}=\beta_{0}+\beta_{1} x_{i 1}+\beta_{2} x_{i 2}+\cdots+\beta_{k} x_{i k}+\epsilon_{i} .
\end{gathered}
$$

Stepwise regression analysis is simply a combination of backward and forward procedures and is probably the most preferable approach [10] when there are a large number of independent predictor variables that might have an effect on the response variable. The main reason for applying stepwise regression analysis in this study is that we have a large number of input variables. The larger is number of input variables, the greater are the benefits shown by stepwise regression [30, 39]. 
Çakıt E. et al: A neural network approach for assessing the relationship...

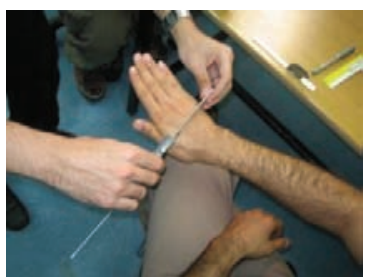

(a)

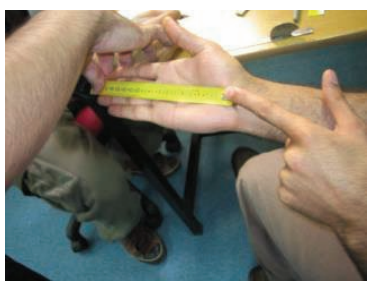

(d)

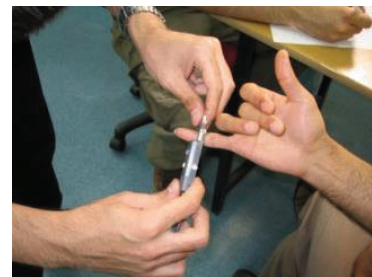

(b)

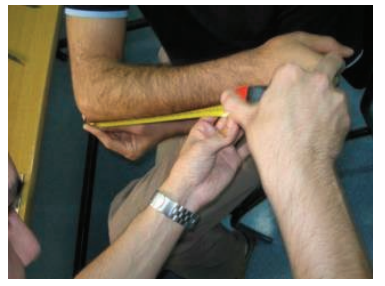

(e)

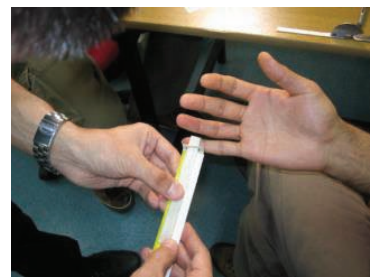

(c)

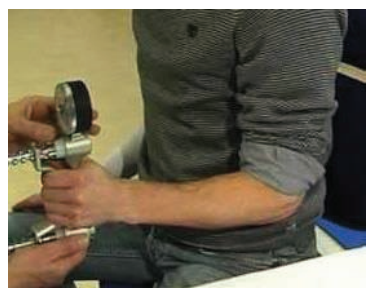

(f)

Fig. 1 Hand dimensions and grip strength; refer to definitions in Tab. I. (a) Hand breadth, (b) Finger breadth, (c) Finger circumference, (d) Hand length, (e) Forearm length, (f) Grip strength.

Stepwise regression analysis looks at one particular question: whether or not removing a particular independent variable reduces the predictive efficiency of the model [36]. Stepwise regression is a type of multiple regression analysis. However, it differs from the standard multiple regression techniques. Stepwise regression introduces independent variables sequentially based on partial- $F$ statistics; therefore, the best model is selected according to the most significant variables. During this iteration, the accuracy of the selected model is not affected significantly [27]. If $F>F_{\alpha}$ (the variable included is statistically significant), the variable should be entered in this equation. If $F<F_{\alpha}$ (the variable is not significant), and the final model constitutes the equation from the previous iteration.

\subsubsection{Brief overview of ANNs and model parameters}

ANNs are mathematical models of the human brain that mimic the functioning mechanism of biological neural networks. Basically, ANN performs the function of nonlinear mapping or pattern recognition. In other words, by using ANN it is possible to model complex and non-linear systems [34]. The proper selection of neural network architecture is a crucial decision for accurate prediction $[41,21]$.

In this study, three different types of ANN topologies were used and compared with each other: Multilayer perceptron (MLP), Radial Basis Function (RBF), and Generalized Feed Forward (GFF). All these neural network architectures were constructed with one and two hidden layers, with two training (weight update) algorithms of batch versus online (incremental), and two different algorithms (L: Levenberg-Marquardt, M: Momentum) were applied in order to identify the best training result. 
The summary of parameters defined in this research is as follows:

- number of hidden layers $=1,2$,

- number of neurons in a hidden layer $=$ varies from 1 to 50 ,

- number of output layer units $=1$,

- momentum coefficient $=0.6$,

- learning rate $=0.3$,

- maximum number of epochs to train $=1000$,

- error goal to stop training $=0$.

\subsubsection{Performance metrics}

Performance metrics were used for calculating the error (difference between actual and predicted values) in the model. There are several performance metrics including coefficient of determination $\left(R^{2}\right)$, mean square error (MSE), root mean square error (RMSE), mean absolute error (MAE), and mean absolute error (MAE).

In this research, and in order to calculate the performance of ANN models, model accuracy was evaluated based on the coefficient of determination $\left(R^{2}\right)$, RMSE, and MAE values between the predicted and actual values. The following Eqs. (2), (3) and (4) were used for this calculation:

$$
\begin{array}{r}
R^{2}=1-\left(\frac{\sum_{i=1}^{n}\left(P_{i}-A_{i}\right)^{2}}{\sum_{i=1}^{n} A_{i}^{2}}\right) \\
\mathrm{RMSE}=\sqrt{\frac{1}{n} \sum_{i=1}^{n}\left(P_{i}-A_{i}\right)^{2},} \\
\mathrm{MAE}=\frac{1}{n} \sum_{i=1}^{n}\left|\left(P_{i}-A_{i}\right)\right|
\end{array}
$$

where $A_{i}$ and $P_{i}$ were the actual and predicted values, respectively, $n$ is the total number of testing records, and $i=1,2,3, \ldots, n$.

\subsubsection{Sensitivity analysis}

Sensitivity analysis was performed based on trained ANNs and implemented as an approach to determine the cause and effect relationship between the independent and dependent variables [7]. In sensitivity analysis, a matrix of values was created containing information for each input/output combination computed as a percentage such that the sum of all sensitivity values for a particular output totals $100 \%$ [31]. 
Çakıt E. et al: A neural network approach for assessing the relationship...

While evaluating sensitivity analysis, the learning unit needs to be in off-mode so that the network weights are unchanged. The main purpose is to track the percentage change in the output value after a small change in the input value [35].

Except for the first input value, the remaining input values are not changed based on their mean values. The output value is calculated based on the percentage change of the corresponding mean value. The calculation step is repeated and summarized for each input and output value based on the variation difference [40]. This research was conducted according to the sequence of steps illustrated in Fig. 2.

\section{Results and discussion}

\subsection{Descriptive statistics and differences between populations}

As a starting point, we performed the basic descriptive statistical analysis, including mean and standard deviation of the input and output variables used in the model construction (Tab. II). Handgrip strength was used to compare with Indian ( $\mathrm{n}=$ 95 female) [28], South Indian ( $\mathrm{n}=128$ male) [14], Jordanian $(\mathrm{n}=120$ female, $\mathrm{n}=$ 115 male) [24], American $(\mathrm{n}=26$ female, $\mathrm{n}=29$ male) [26], Malaysian $(\mathrm{n}=212$ male) [20] and British ( $\mathrm{n}=92$ female) [8] populations.

\begin{tabular}{lrrrr}
\hline \multirow{2}{*}{ Hand dimensions $[\mathrm{mm}]$ and grip strength $[\mathrm{kg}]$} & \multicolumn{3}{c}{ Females $(\mathrm{n}=72)$} & \multicolumn{2}{c}{ Males $(\mathrm{n}=81)$} \\
& Mean & SD & Mean & SD \\
\hline Breadth at first joint of digit 5 & 11.96 & 0.64 & 13.96 & 0.78 \\
Circumference at first joint of digit 5 & 38.07 & 3.19 & 44.41 & 3.13 \\
Hand breadth across thumb & 91.48 & 5.09 & 104.51 & 6.06 \\
Hand length & 172.18 & 8.14 & 190.67 & 9.84 \\
Forearm length & 248.97 & 15.38 & 273.98 & 16.20 \\
Grip Strength & 27.06 & 4.27 & 43.45 & 6.34 \\
\hline
\end{tabular}

Tab. II Descriptive statistics of input and output variables used in the model construction.

Based on the comparison results, the handgrip strength of Turkish males were significantly stronger than South Indian males and significantly weaker than American males. The handgrip strengths of Turkish females were significantly stronger than other populations except for British females. These differences have implications for use of hand tools that have been designed based on the anthropometry and biomechanics of the industrialized countries' (ICs') home population and exported for local use in Turkey (Tabs. III, IV, V and VI).

\subsection{Stepwise regression analysis}

Partial $F$ statistics were calculated for each step at a five percent level of significance for model selection. To elucidate the gender effect, additional stepwise 
Neural Network World 6/15, 603-622

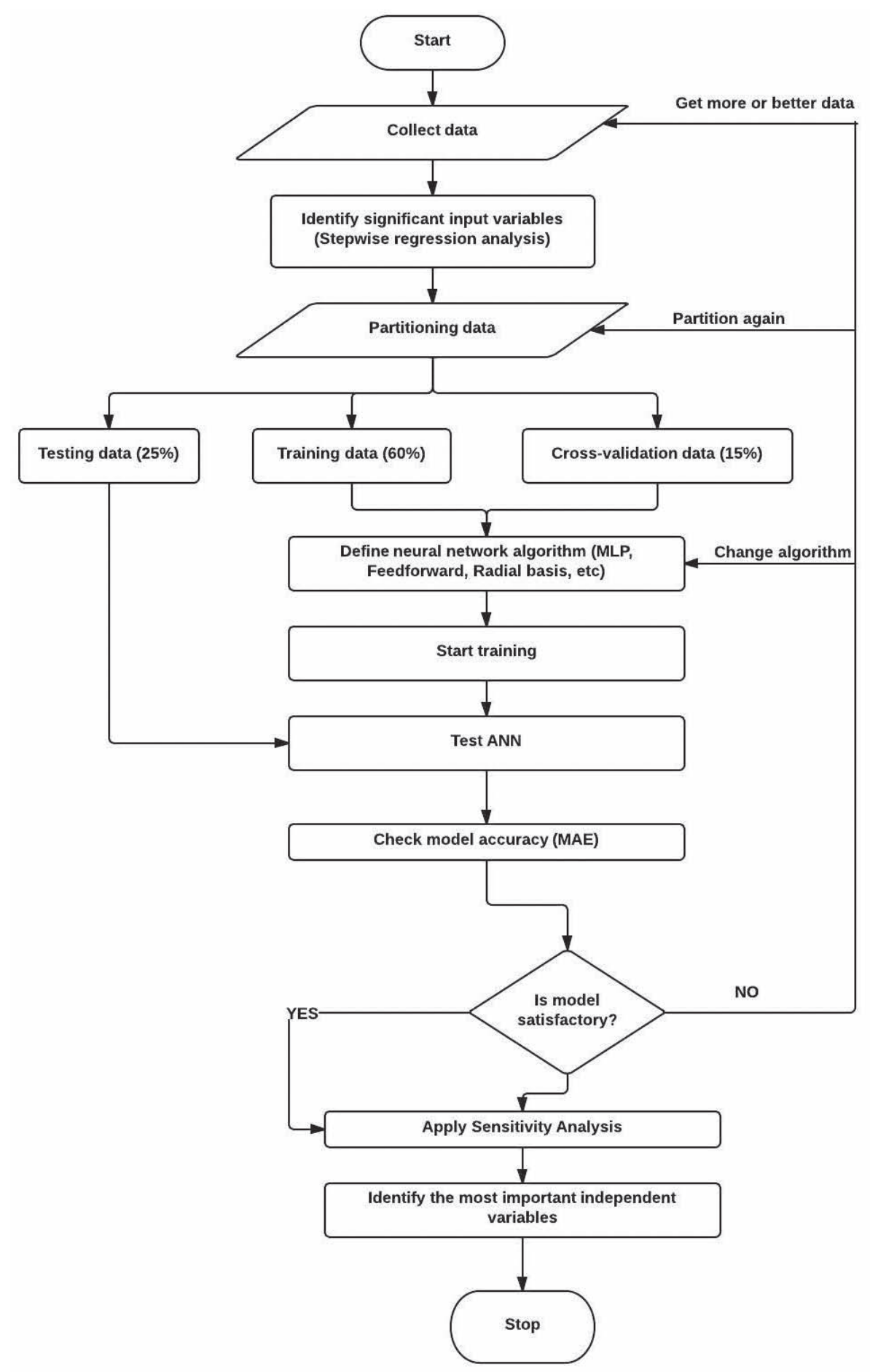

Fig. 2 ANN flow diagram used in this study. 
Çakıt E. et al: A neural network approach for assessing the relationship...

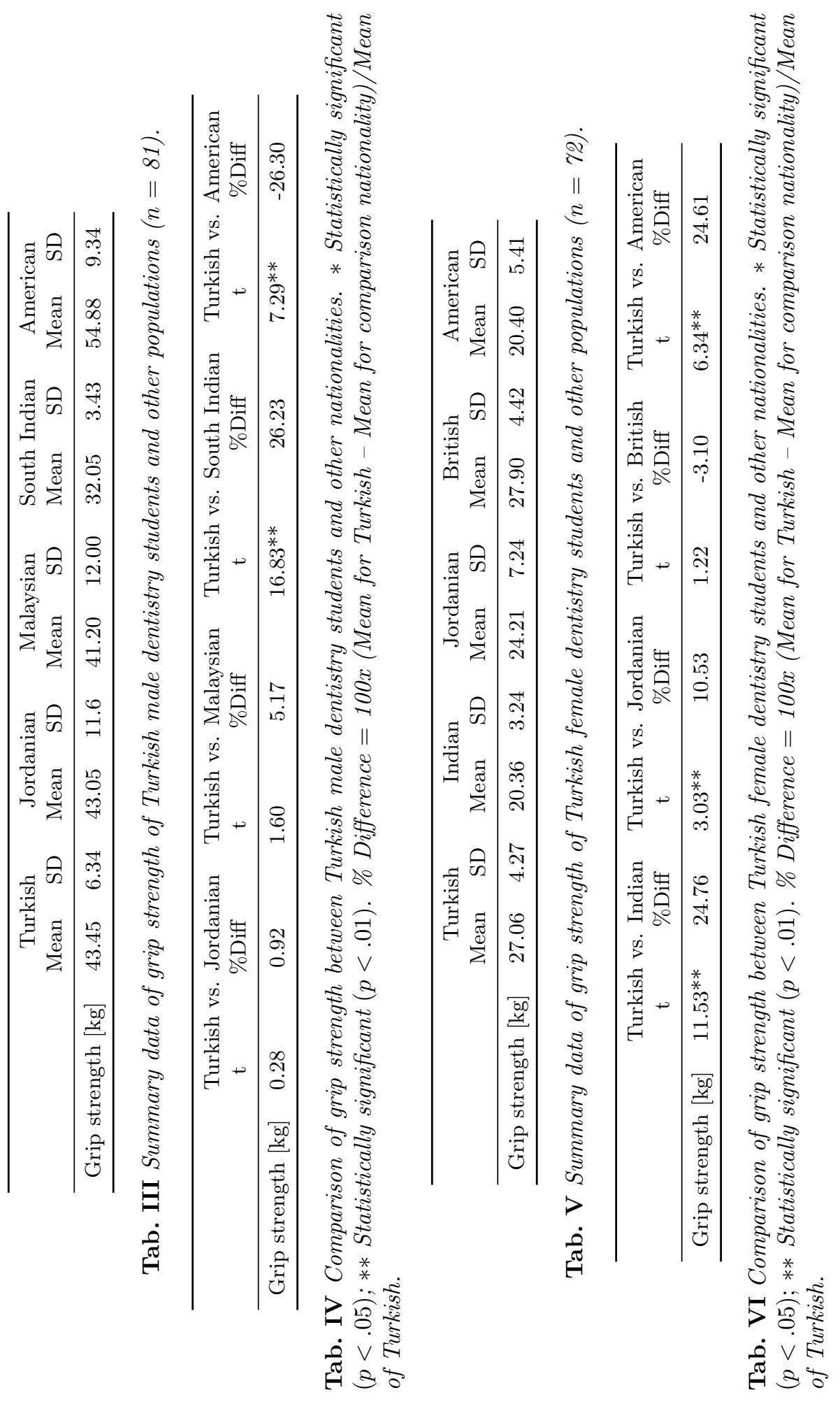


regression analyses were conducted separately for males and females. These preliminary analyses indicated that the only difference on independent variables was finger circumference. A larger proportion of the population (both males and females) input variables were therefore included to improve the accuracy and reliability of the prediction of hand grip strength. Based on the combined gender analysis; finger breadth, hand length, finger circumference, forearm length, and hand breadth are the only significant predictive variables identified by the partial $F$ statistics. All these analyses were conducted using the SPSS software package (Version 18.0 for Windows). Tab. II shows the descriptive statistics for all inputs chosen for estimation.

In this model, the major variability was explained by the five independent variables. The prediction equation of grip strength with breadth at the first joint of digit $5\left(x_{1}\right)$, hand length $\left(x_{2}\right)$, circumference at the first joint of digit $5\left(x_{3}\right)$, forearm length $\left(x_{4}\right)$, and hand breadth across thumb $\left(x_{5}\right)$ is as follows:

$$
y_{i}=1.547 x_{1}+0.111 x_{2}+0.506 x_{3}+0.125 x_{4}+0.252 x_{5}-83.054 .
$$

As seen from the regression equation above, all independent variables affected hand grip strength positively.

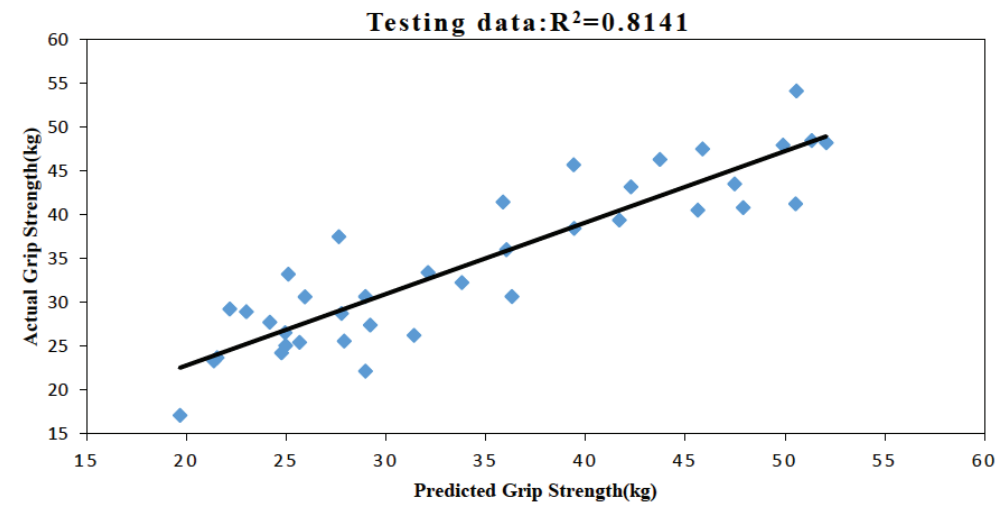

Fig. 3 Regression plot between actual and predicted test data of the grip strength $(n=38)$.

Predicted versus measured (actual) grip strength testing data and complete data are plotted in Figs. 3 and 4 , respectively. The $R$-squared value of the prediction by the regression model on the test data is 0.8141 (Fig. 3). The result from analysis using pairwise $t$-test shows that there was no significant difference at the alpha value of $0.05(p=0.946)$ between actual and predicted grip strength testing data based on the regression analysis (Fig. 3).

The $R$-squared value of the prediction by the regression model on all data is also included. As can be seen from Fig. 4, the coefficient of determination $\left(R^{2}\right)$ between actual and predicted grip strength data based on the regression model is 0.754 . We can conclude that Fig. 3 demonstrates that the predicted versus measured grip strength testing data fits the target line (predicted equal to measured) better than what is the case for complete grip strength data in Fig. 4. 


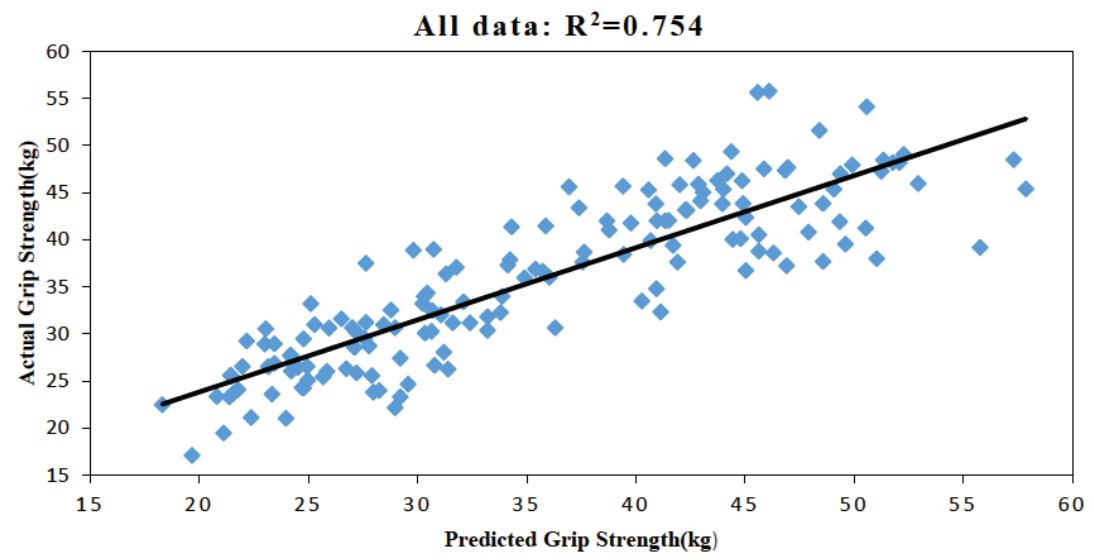

Fig. 4 Regression plot between actual and predicted grip strength data $(n=153)$.

The result from analysis using a pairwise $t$-test shows that there was no significant difference at the alpha value of $0.05(p=0.954)$ between actual and predicted grip strength data based on the regression analysis (Fig. 4).

\subsection{ANN model development}

The selected independent variables were used as inputs in the neural networks. The first issue here is the division of the data into the training, cross-validation and test sets. We used an 'N-fold cross validation' method to interrogate the dataset. Using this method, 153 samples were randomly divided into three groups: 92 samples were used as a training parameter $(153 \times 0.6 \approx 92), 23$ samples for cross-validation $(153 \times 0.15 \approx 23)$ and 38 samples $(153 \times 0.25 \approx 38)$ were used as a testing parameter. We used the 'Leave $\mathrm{N}$ out' option. This allows use of the entire data set for model validation, re-training the "best" model up to one hundred times with the final result being completely out of sample [31].

The initial weights are usually randomly selected while designing neural networks [42]. The use of varied random initial weights on each run could generate different outcomes [6]. They are adjusted continuously up to their best values as the network learns from the inputted data and adapts its output data accordingly. In our study, five independent runs were made on each topological model in order to get the best result.

A total of twelve different combinations were determined by using Neuro-Solutions software (v. 6.27 Neuro Dimension Inc., Gainesville, Florida, USA). The model results obtained for the data set in terms of the coefficient of determination $\left(R^{2}\right)$, RMSE, and MAE are presented in Tab. VII. From this result, it may be observed that MLP-2-O-M (Multilayer perceptron with two hidden layers and online processing using the Momentum algorithm) model produced better prediction than other models.

The training and cross validation report for MLP-2-O-M model is shown in Fig. 5. The training and cross validation termination criterion was set at mean 
Neural Network World 6/15, 603-622

\begin{tabular}{lccccccccc}
\hline Model & \multicolumn{3}{c}{ Training } & \multicolumn{3}{c}{ Cross validation } & \multicolumn{3}{c}{ Testing } \\
& RMSE & $\mathrm{R}^{2}$ & MAE & RMSE & $\mathrm{R}^{2}$ & MAE & RMSE & $\mathrm{R}^{2}$ & MAE \\
\hline MLP-1-O-M & 4.69 & 0.783 & 3.57 & 5.19 & 0.659 & 3.81 & 4.06 & 0.845 & 3.29 \\
MLP-1-B-L & 4.22 & 0.821 & 3.40 & 5.03 & 0.645 & 4.00 & 4.14 & 0.837 & 3.40 \\
RBF-1-B-L & 4.61 & 0.785 & 3.61 & 4.57 & 0.707 & 3.57 & 3.97 & 0.846 & 3.16 \\
GFF-1-B-L & 4.41 & 0.805 & 3.50 & 5.04 & 0.650 & 3.91 & 4.16 & 0.832 & 3.49 \\
MLP-2-B-L & 5.50 & 0.778 & 4.80 & 5.35 & 0.612 & 4.30 & 5.65 & 0.731 & 4.42 \\
MLP-1-B-M & 5.87 & 0.697 & 4.65 & 4.44 & 0.729 & 3.31 & 5.29 & 0.746 & 4.03 \\
MLP-2-O-M & $\mathbf{4 . 4 7}$ & $\mathbf{0 . 8 0 1}$ & $\mathbf{3 . 4 7}$ & $\mathbf{5 . 1 0}$ & $\mathbf{0 . 6 6 7}$ & $\mathbf{3 . 8 7}$ & $\mathbf{3 . 8 4}$ & $\mathbf{0 . 8 5 8}$ & $\mathbf{3 . 2 0}$ \\
MLP-2-B-M & 5.10 & 0.741 & 4.09 & 4.49 & 0.723 & 3.12 & 4.59 & 0.801 & 3.55 \\
GFF-1-O-M & 4.74 & 0.783 & 3.52 & 5.57 & 0.632 & 4.01 & 4.01 & 0.854 & 3.24 \\
GFF-1-B-M & 5.75 & 0.686 & 4.62 & 4.25 & 0.745 & 2.98 & 5.24 & 0.736 & 3.96 \\
RBF-1-O-M & 4.90 & 0.757 & 3.78 & 4.29 & 0.759 & 3.15 & 4.44 & 0.812 & 3.45 \\
RBF-1-B-M & 5.80 & 0.738 & 4.60 & 5.14 & 0.707 & 4.34 & 5.62 & 0.780 & 4.71 \\
\hline
\end{tabular}

Tab. VII Comparison of different neural network architectures.

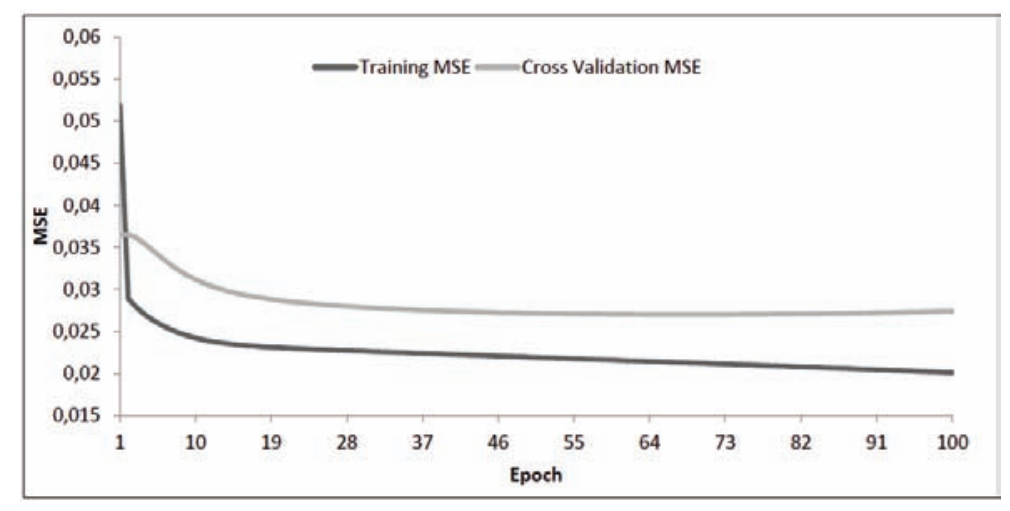

Fig. 5 Change in training and cross validation MSE values versus epoch values of MLP-2-O-M model.

square error (MSE) of 0.01 . The validity of the ANN model was tested by using the same performance measures.

The comparison of desired and MLP-2-O-M neural network output is illustrated in Fig. 6. It was shown that the neural network outputs closely follow the actual values.

Fig. 7 provides information about the coefficient of determination $\left(R^{2}\right)$ between actual and predicted grip strength testing data based on the best topology of the ANN model. The testing values of the models correlated well with the actual values, with coefficient of determination $\left(R^{2}\right)$ of 0.8587 which indicated that the ANN model can accurately predict the grip strength with respect to the actual values. The results from analysis using the pairwise $t$-test shows that there was no significant difference at the alpha value of $0.05(p=0.841)$ between actual and predicted grip strength testing data based on the ANN network (Fig. 7). 
Çakıt E. et al: A neural network approach for assessing the relationship...

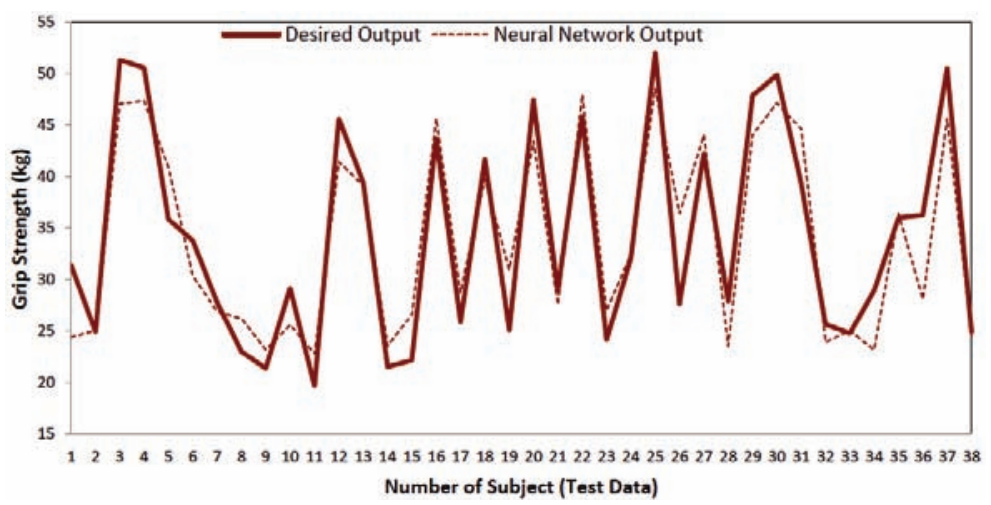

Fig. 6 Comparison of desired and MLP-2-O-M neural network outputs.

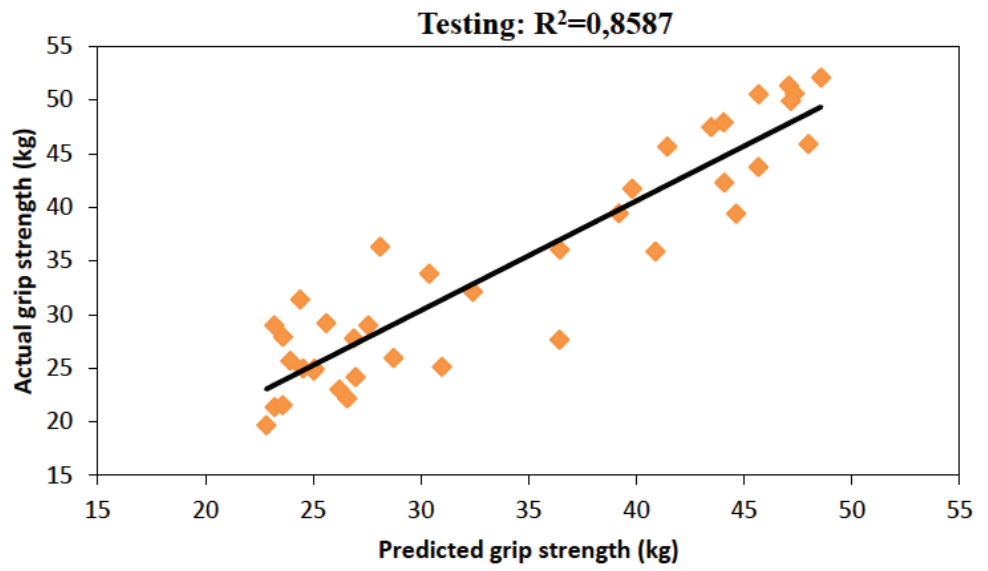

Fig. 7 Coefficient of determination $\left(R^{2}\right)$ between actual and predicted grip strength testing data based on the ANN network.

To see all the values, the $R$-square of the prediction by the ANN model on all data is included. As can be seen from Fig. 8, the coefficient of determination $\left(R^{2}\right)$ between actual and predicted grip strength data based on the ANN model is 0.8027 .

The result from analysis using pairwise $t$-test shows that there was no significant difference at the alpha value of $0.05(p=0.516)$ between actual and predicted grip strength data based on the ANN network (Fig. 8).

\subsection{Performance comparison of models}

To determine the most accurate approach between the two methodologies applied in this research, both models were compared to each other on the same basis using performance metrics. When the model accuracy was calculated based on the $\mathrm{R}^{2}$, RMSE, and MAE values, the ANN model demonstrated better predictive accuracy 


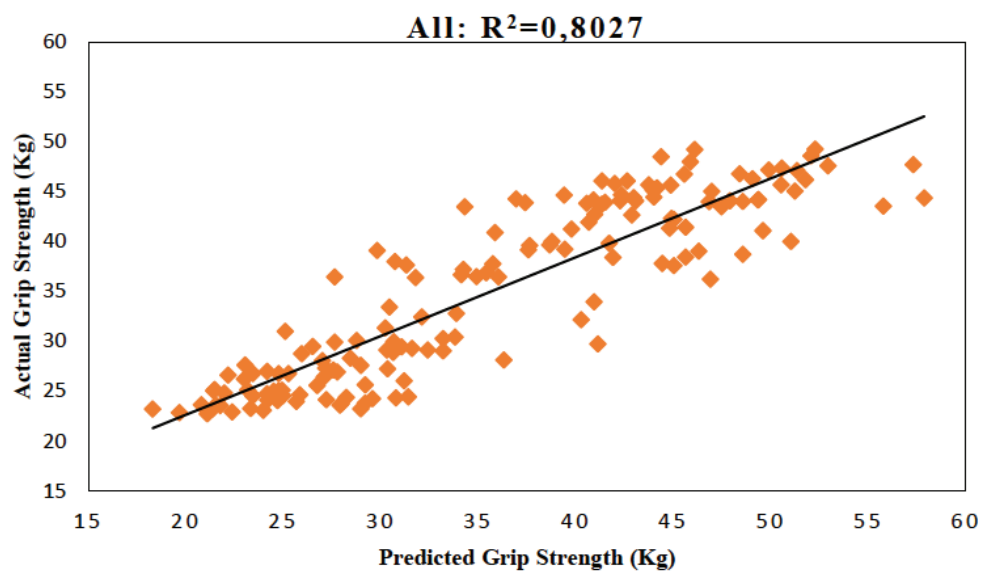

Fig. 8 Coefficient of determination $\left(R^{2}\right)$ between actual and predicted grip strength data based on the ANN network.

than stepwise regression analysis for predicting grip strength (Tab. VIII). By using ANN it is possible to model complex and non-linear systems. Thus, this was an expected result, mainly because the grip strength depends on many different hand anthropometric variables, and the relations between these factors are highly nonlinear and complex.

\begin{tabular}{lrrrrrr}
\hline & \multicolumn{3}{c}{ ANN } & \multicolumn{3}{c}{ Stepwise regression analysis } \\
& MAE & $\mathrm{R}^{2}$ & RMSE & MAE & $\mathrm{R}^{2}$ & RMSE \\
\hline Testing data $(n=38)$ & 3,21 & 0.8581 & 3.84 & 3.51 & 0.8141 & 4.37 \\
All data $(n=153)$ & 3.46 & 0.8027 & 4.42 & 3.85 & 0.754 & 4.89 \\
\hline
\end{tabular}

Tab. VIII Performance comparison of ANN and stepwise regression models.

\subsection{Sensitivity analysis results}

In the previous section, ANN was noted as the best predictive model for the dependent variable based on performance values. Thus, sensitivity analysis was performed, based on the trained ANN and developed under NeuroSolutions, version 6.27. A sensitivity analysis was conducted using the best network (MLP-2-O-M) selected to identify the degree to which the independent variables (inputs or hand breadth, finger breadth, hand length, finger circumference and forearm length) contribute to the determination of the dependent variable (grip strength). Based on the sensitivity analysis results, the effect of each input variable of developed ANN model on predicted were ranked based on the normalized sensitivity weights.

Grip strength value increased while all independent values increased. Fig. 9 illustrates the sensitivity of input variables versus grip strength. Based on the results in Fig. 9, three input variables, namely the forearm length, the hand breadth 
Çakıt E. et al: A neural network approach for assessing the relationship...

and the finger circumference at the first joint of the 5 -th digit were found to be the most effective parameters (i.e., contributed more than $70 \%$ of the normalized sensitive weightings). Conversely, finger breadth at the first joint of the 5 -th digit and hand length, were found to be the least effective parameters.

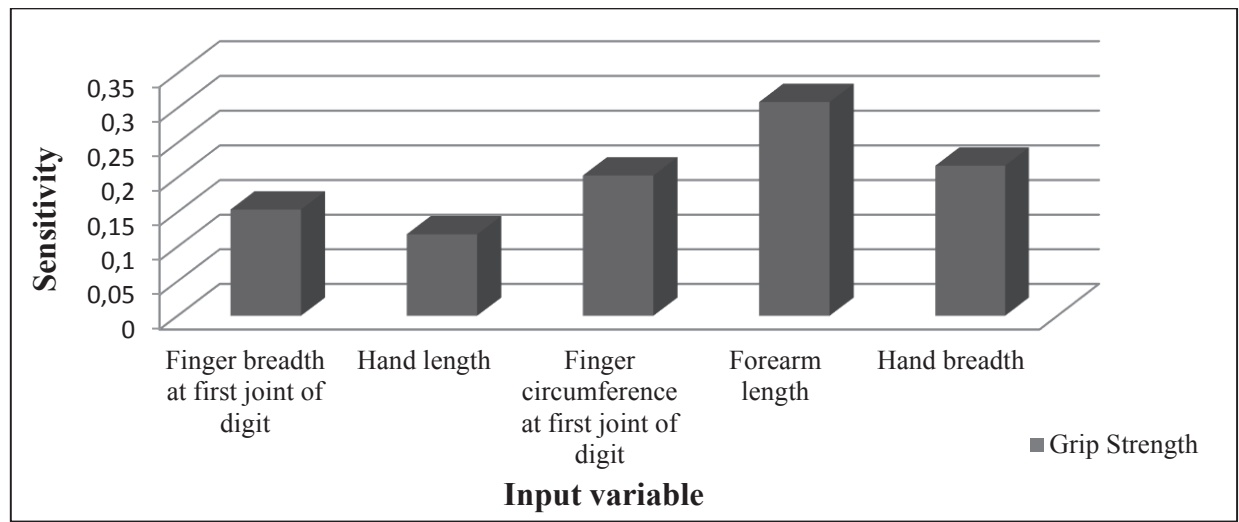

Fig. 9 Sensitivity of input variables versus grip strength output.

A neural network model development needs a significant statistical analysis in order to understand the data and process flows [13]. To compute the performance of the ANN and regression models, the set of independent variables for hand grip strength have been selected by stepwise regression analysis and were used as inputs for both models. Until now there have been several studies conducting stepwise regression analysis before applying the neural network modeling [5, 22, 38, 46, and 1]. It must be stated that stepwise regression analysis may not be the optimum one for ANN, and different approaches should be tried for further studies. As the training of ANN is a continuous process, the databank should also be updated by measuring new dimensions for a better-trained ANN. Furthermore, the developed ANN model can be used to examine the importance of hand anthropometry for gripping and might have important applications in hand tool design for manual handling. A larger sample of data, including dentists, might be considered as a future work to better differentiate age characteristics.

\subsection{Comparison with previous models}

A larger proportion of the population (both males and females) as input variables were included to improve the accuracy and reliability of the prediction hand grip strength. Thus, the gender effect was not considered and grip strength was predicted for all participants (both genders).

We compared predicting accuracy based on the RMSE values to gain knowledge about the predictive power of the neural network and regression model built in this study, in comparison to previous studies [48, 16, 17, and 44]. The current study and Wang et al. (1987) [48] included only hand anthropometric variables; Hanten et al. (1999) [16] and Hossain et al. (2011) [17] included other easily obtainable variables other than hand anthropometric variables. Recently, Sung et al. (2015) 
[44] included hand anthropometric and other variables. Based on the results of combined gender analysis in Tab. IX, the calculated RMSEs of both genders were 4.37 and 3.84, indicating that the predictive accuracy for regression and ANN models generated in current study demonstrated better predictive accuracy than the models in previous studies.

\begin{tabular}{lc}
\hline Prediction models & $\begin{array}{c}\text { RMSE values for all participants } \\
\text { (both males and females) }\end{array}$ \\
\hline Current Study (ANNs) & 3.84 \\
Current Study (Regression) & 4.37 \\
Wang et. al. (1987) & 146.80 \\
Hanten et.al. (1999) & 65.79 \\
Hossain et al. (2011) & 172.91 \\
Sung et al. (2015) (ANNs) & 11.75 \\
Sung et al. (2015) (Regression) & 36.06 \\
\hline
\end{tabular}

Tab. IX Comparison of grip strength prediction accuracy based on RMSE values.

\section{Conclusions}

In this study, ANN modeling approach has been employed to relate hand breadth, finger breadth, hand length, finger circumference and forearm length to hand grip strength. When the performance values were computed, the predicted values generated by ANN were found to be satisfactory. This implied that the five input variables selected were reliable in predicting the grip strength. In addition to the ANN model, we performed a stepwise regression analysis to have an idea about the predictive power of the neural network approach, in comparison to a classical statistical approach. When the model accuracy was calculated based on the coefficient of determination $\left(R^{2}\right)$, the root mean squared error (RMSE) and the mean absolute error (MAE) values for each of the models, ANN had better predictive accuracy than regression analysis, as demonstrated by experimental results. In addition, this finding was extended by the three most sensitive input variables identified by the sensitivity analysis on the best network selected. The three most sensitive variables, which together contributed more than $70 \%$ of the normalized sensitive weightings, were the forearm length, the hand breadth and the circumference at first joint of digit 5 . It was found that grip strength value increased while all the independent values increased.

Based on the grip strength protocol described in previous sections, the direct measurement of grip strength requires considerable motivation on the part of the subject. For this reason, direct measurement of the grip strength takes considerable time when a sample size is too large. In this study, all data (forty-four hand anthropometric and biomechanics measurements) were collected over a period of two months. The authors had estimated the time used to measure the five hand dimensions. Based on our study population $(\mathrm{n}=153)$, it took at least one week 
Çakıt E. et al: A neural network approach for assessing the relationship...

to complete all participants measurements, depending on the subject's availability. Thus, we claimed that estimating grip strength by measuring the five chosen anthropometric measurements is less time-consuming than direct measurement by dynamometer. On the other hand, training data should include large number of sample group because of the act that the reliability of neural network approach depends heavily on being able to learn from past events. Thus, adopting a predictive model may not be suitable and reliable for a small subject group, such as 10 to 20 participants.

In summary, ANN and stepwise regression analysis examined the relationship between grip strength and hand anthropometry. We concluded that there is a strong influence of hand anthropometric variables on grip strength. On the basis of the results obtained, with the help of ANN, we can predict the hand grip strength easily and accurately based on various hand dimensions.

\section{Acknowledgement}

The authors acknowledge the generous support from Cukurova University Academic Research Projects Unit toward the research underlying this paper. The authors wish to thank Faculty of Dentistry at the Cukurova University for their assistance with data collection.

\section{References}

[1] AMBALAVANAN N., CARLO W.A. Comparison of the prediction of extremely low birth weight neonatal mortality by regression analysis and by neural networks. Early human development. 2001, 65(2), pp. 123-137, doi: 10.1016/s0378-3782(01)00228-6.

[2] BOISSY P., BOURBONNAIS D., CARLOTti M.M., GRAVEL D., ARSENAUlT B.A. Maximal grip force in chronic stroke subjects and its relationship to global upper extremity function. Clinical Rehabilitation. 1999, 13(4), pp. 354-362, doi: 10.1191/ 026921599676433080.

[3] CAKIT E., DURGUN B., CETIK O., YOLDAS O. A survey of hand anthropometry and biomechanical measurements of dentistry students in Turkey. Human Factors and Ergonomics in Manufacturing $\mathscr{G}$ Service Industries. 2014, 24(6), pp. 739-753, doi: 10.1002/ $\mathrm{hfm} .20401$.

[4] CHAFFIN D.B., PARK K.S. A longitudinal study of low-back pain as associated with occupational weight lifting factors. The American Industrial Hygiene Association Journal. 1973, 34(12), pp. 513-525, doi: 10.1080/0002889738506892.

[5] CHAlOUlakOU A., GRIVAS G., SPYRELLIS N. Neural network and multiple regression models for PM10 prediction in Athens: a comparative assessment. Journal of the Air 83 Waste Management Association. 2003, 53(10), pp. 1183-1190, doi: 10.1080/10473289.2003. 10466276

[6] CHEN S.M., WANG Y.M., TSOU I. Using artificial neural network approach for modelling rainfall-runoff due to typhoon. Journal of Earth System Science. 2013, 122(2), pp. 399-405, doi: $10.1007 / \mathrm{s} 12040-013-0289-8$.

[7] ÇAKIT E., KARWOWSKI W., BOZKURT H., AHRAM T., THOMPSON W., MIKUSINSKI P., LEE G. Investigating the relationship between adverse events and infrastructure development in an active war theater using soft computing techniques. Applied Soft Computing. 2014, 25, pp. 204-214, doi: 10.1016/j.asoc.2014.09.028.

[8] DAVies B.T., ABADA A., BEnSOn K., COURTney A., Minto I. Female hand dimensions and guarding of machines. Ergonomics. 1980, 23(1), pp. 79-84, doi: 10.1080/ 00140138008924720 . 


\section{Neural Network World 6/15, 603-622}

[9] DIDOMENICO A., NUSSBAUM M.A. Measurement and prediction of single and multi-digit finger strength. Ergonomics. 2003, 46(15), pp. 1531-1548, doi: 10.1080/ 0014013032000121660.

[10] DRAPER N.R., SMITH H., POWNELL E. Applied regression analysis. New York: Wiley, vol. 3, 1966.

[11] DUBROWSKI A., CARNAHAN H. Grip force when grasping moving cylinders. International journal of industrial ergonomics. 2004, 34(2), pp. 69-76, doi: 10.1016/j . ergon. 2004. 03.001.

[12] EKSIOGLU M., FERNANDEZ J.E., TWOMEY J.M. Predicting peak pinch strength: artificial neural networks vs. regression. International Journal of Industrial Ergonomics. 1996, 18(5), pp. 431-441, doi: 10.1016/0169-8141(95) 00106-9.

[13] FEDENCZUK L.L. To neural or not to neural? - This is the question. In: Proceedings of the Twenty-Seventh Annual SAS®Users Group International Conference (SUGI'27), Orlando, Florida, USA. SAS Institute Inc., Cary, NC, 2002, paper 113-27.

[14] FERNANDEZ J.E., UPPUGONDURI K.G. Anthropometry of South Indian industrial workmen. Ergonomics. 1992, 35(11), pp. 1393-1398, doi: 10.1080/00140139208967400.

[15] FESS E.E. Grip strength. In: J.S. Casanova JS, ed. Clinical assessment recommendations. 2nd ed. Chicago: American Society of Hand Therapists, 1992, pp. 41-45.

[16] HANTEN W.P., CHEN W.Y., AUSTIN A.A., BROOKS R.E., CARTER H.C., LAW C.A., MORGAN M.K., SANDERS D.J, SWAN C.A., VANDERSLICE A.L. Maximum grip strength in normal subjects from 20 to 64 years of age. J Hand Surg. 1999, 12(3), pp. 193-200, doi: 10.1016/s0894-1130(99)80046-5.

[17] HOSSAIN M.G., ZYROUL R., PEREIRA B.P., KAMARUL T. Multiple regression analysis of factors influencing dominant hand grip strength in an adult Malaysian population. $J$ Hand Surg (European volume). 2012, 37(1), pp. 65-70, doi: 10.1177/1753193411414639.

[18] ISO 7250. Basic human body measurements for technological design. International Standard, 1996.

[19] JÜRIMÄE T., HURBO T., JÜRIMÄE J. Relationship of handgrip strength with anthropometric and body composition variables in prepubertal children. HOMO-Journal of Comparative Human Biology. 2009, 60(3), pp. 225-238, doi: 10.1016/j.jchb.2008.05.004.

[20] KAMARUL T., AHMAD T.S., LOH W.Y.C. Normal hand grip strength in the adult Malaysian population. Journal of Orthopaedic Surgery. 2006, 14(2), pp. 172-177.

[21] KHALAJ G., NAZARI A., POURALIAKBAR H. Prediction of martensite fraction of microalloyed steel by artificial neural networks. Neural Network World. 2013, 23(2), pp. 117-130, doi: 10.14311/nnw.2013.23.009.

[22] KIM G.H., AN S.H., KANG K.I. Comparison of construction cost estimating models based on regression analysis, neural networks, and case-based reasoning. Building and environment. 2004, 39(10), pp. 1235-1242, doi: 10.1016/j. buildenv. 2004.02.013.

[23] LEE S.J., KONG Y.K., LOWE B.D., SONG S. Handle grip span for optimizing finger-specific force capability as a function of hand size. Ergonomics. 2009, 52(5), pp. 601-608, doi: 10. 1080/00140130802422481.

[24] MANDAHAWI N., IMRHAN S., AL-SHOBAKI S., SARDER B. Hand anthropometry survey for the Jordanian population. Industrial Journal of Industrial Ergonomics. 2008, 38(11-12), pp. 966-976, doi: 10.1016/j.ergon.2008.01.010.

[25] MASSY-WESTROPP N., RANKIN W., AHERN M., KRISHNAN J., HEARN T.C. Measuring grip strength in normal adults: reference ranges and a comparison of electronic and hydraulic instruments. The Journal of hand surgery. 2004, 29(3), pp. 514-519, doi: 10.1016/ j.jhsa.2004.01.012.

[26] MATHIOWETZ V., KASHMAN N., VOLLAND G., WEBER K., DOWE M., ROGERS S. Grip and pinch strength: Normative datafor adults. Archives of Physical Medicine and Rehabilitation. 1985, 66, pp. 69-72.

[27] MCCUEN R.H. Microcomputer applications in statistical hydrology. Engle-wood Cliffs. NJ: Prentice Hall, 1993. 
Çakıt E. et al: A neural network approach for assessing the relationship...

[28] NAG A., NAG P.K., DESAI H. Hand anthropometry of Indian women. Indian Journal of Medical Research. 2003, 117, pp. 260-269.

[29] NASA. Anthropometric Source Book. Volume 2: A handbook of anthropometric data. Aeromatics and Space Administration Washington, 1978. Available from: http://ntrs.nasa. gov/archive/nasa/casi.ntrs.nasa.gov/19790005541.pdf

[30] NETER J., KUTNER M.H., NACHTSHEIM C.J., WASSERMAN W. Applied linear regression models. USA: Richard D. Irwin, Inc., 1996.

[31] NEUROSOLUTiOns DOCUMENTATION. Available from: http://www. neurosolutions. com/docs/NeuroSolutions.pdf

[32] NEVILL A.M., HOLDER R.L. Modelling handgrip strength in the presence of confounding variables: results from the Allied Dunbar National Fitness Survey. Ergonomics. 2000, 43(10), pp. 1547-1558, doi: 10.1080/001401300750003970.

[33] NICOLAY C.W., WALKER A.L. Grip strength and endurance: Influences of anthropometric variation, hand dominance, and gender. International Journal of Industrial Ergonomics. 2005, 35(7), pp. 605-618, doi: 10.1016/j.ergon.2005.01.007.

[34] ODABAS M.S., LEELARUBAN N., SIMSEK H., PADMANABHAN G. Quantifying impact of droughts on barley yield in North Dakota, USA using multiple linear regression and artificial neural network. Neural Network World. 2014, 24(4), pp. 343-355, doi: 10.14311/ nnw. 2014.24.020.

[35] PRINCIPE J.C., EULIANO N.R., LEFEBVRE W.C. Neural and adaptive systems: fundamentals through simulations with CD-ROM. John Wiley \& Sons, Inc., 1999.

[36] PUNCH K.F. Introduction to social research: Quantitative and qualitative approaches. 2nd ed. Sage, 2005.

[37] SAENGCHAIYA N., BUNTERNGCHIT Y. Hand anthropometry of Thai female industrial workers. The journal of KMITNB. 2004, 14(1), pp. 16-19.

[38] SALCHENGERGER L.M., CINAR E.M., LASH N.A. Neural networks: A new tool for predicting thrift failures. Decision Sciences. 1992, 23(4), pp. 899-916, doi: 10.1111/j. 1540-5915.1992.tb00425.x.

[39] SAltelli A., CHAN K., SCOTT E.M. Sensitivity analysis. UK: Wiley \& Sons Ltd., 2000.

[40] SHARDA R., DELEN D. Predicting box-office success of motion pictures with neural networks. Expert Systems with Applications. 2006, 30(2), pp. 243-254, doi: 10.1016/j.eswa. 2005.07.018.

[41] SHEELA K.G., DEEPA S.N. Review on methods to fix number of hidden neurons in neural networks. Mathematical Problems in Engineering. 2013, 2013, pp. 1-11, doi: 10.1155/2013/ 425740 .

[42] SINGH E. Comparative Economic Forecasting with Neural Networks Forecasting Aggregate Business Sales from SESP 500 and Interest Rates. New York: Pace University, 2007.

[43] SMITH D.A., LUKENS S.A. Stress effects of isometric contraction in occupational therapy. OTJR: Occupation, Participation and Health. 1983, 3(4), pp. 222-242, doi: 10.1177/ 153944928300300404.

[44] SUNG P.C., HSU C.C., LEE C.L., CHIU Y.S.P., CHEN H.L. Formulating grip strength and key pinch strength prediction models for Taiwanese: a comparison between stepwise regression and artificial neural networks. Journal of Ambient Intelligence and Humanized Computing. 2015, pp. 1-10, doi: 10.1007/s12652-014-0245-8.

[45] TAHA Z. Grip strength prediction for Malaysian industrial workers using artificial neural networks. International Journal of Industrial Ergonomics. 2005, 35(9), pp. 807-816, doi: 10. 1016/j.ergon.2004.11.006.

[46] UYSAL M., EL ROUBI M.S. Artificial neural networks versus multiple regression in tourism demand analysis. Journal of Travel Research. 1999, 38(2), pp. 111-118, doi: 10.1177/ 004728759903800203.

[47] VOORBIJ A.I.M., STEENBEKKERS L.P.A. The composition of a graph on the decline of total body strength with age based on pushing, pulling, twisting and gripping force. Applied Ergonomics. 2001, 32(3), pp. 287-292, doi: 10.1016/s0003-6870(00)00068-5. 
[48] WANG M.J., BISHU R.R., RODGERS S.H. Grip strength changes when wearing three types of gloves. In: Proceedings of Interface 87, Rochester, New York. 1987, pp. 349-354.

[49] WU S.W., WU S.F., LIANG H.W., WU Z.T., HUANG S. Measuring factors affecting grip strength in a Taiwan Chinese population and a comparison with consolidated norms. Applied Ergonomics. 2009, 40(4), pp. 811-815, doi: 10.1016/j.apergo.2008.08.006. 